\title{
AC 2011-2066: EVALUATION AND ANALYSIS OF FRESHMAN DESIGN COURSES IN ENGINEERING
}

\section{Tiffany Veltman, University of Calgary}

Tiffany Veltman received her B.Sc in software engineering from the University of Calgary, AB, Canada in June, 2010. Currently, she is pursuing a Master's degree at the University of Calgary, in the field of engineering education research. Specifically, her research is focused on developing qualitative metrics for the assessment of student learning and engineering curriculum.

William (Bill) Rosehart, University of Calgary

Prof. Marjan Eggermont, University of Calgary

Denis Onen, University of Calgary 


\title{
Evaluation and Analysis of Freshman Design Courses in Engineering
}

\begin{abstract}
Design is a crucial component to engineering. Therefore, it is important for engineering students to learn and practice design skills early in their education. At the Schulich School of Engineering, University of Calgary, two implementations of design education were explored; a two-semester design experience with a focus on learning-by-doing, and a single semester experience with a focus on balancing the theoretical foundations of design, communications, and project management, with practical lab workshops.
\end{abstract}

The focus of this paper is the development and evaluation of criteria used to compare these two approaches to a freshman design experience. Using the Canadian Engineering Accreditation Board (CEAB) Graduate Attributes criteria and drawing from the Conceive-Design-ImplementOperate (CDIO) Initiative as the basis for evaluation, a detailed analysis of the strengths and weaknesses of the two design courses in terms of learning outcomes is explored.

Introduction

As technology continues to advance, it becomes increasingly important for engineering graduates to have strong design skills, in order to meet the widely varied requirements of industry ${ }^{1}$. While capstone projects provide senior engineering students with the opportunity to apply their design skills in a large-scale setting, it is first necessary for the students to learn and develop the fundamental skillsets that are used in solving a design challenge. At the Schulich School of Engineering, University of Calgary, first year engineering students participate in an Engineering Design and Communications course, as a means of accelerating their design training, and providing them with a foundation in design that can be built on in subsequent courses leading up to their capstone projects. This paper describes the evaluation and analysis of two implementations of a first-year design course experience.

\section{Initial Design Course}

In 2002, the Schulich School of Engineering, University of Calgary introduced a pair of courses in engineering design and communication. The 2002 design course structure consisted of one design course in each of the two semesters, with an emphasis on laboratory experiences. Through these courses, the students were given 245 minutes of lab time each week (divided into two weekly lab periods of 170 minutes and 75 minutes, respectively) to work on various openended design challenges, as well as 50 minutes each week for lectures, which taught primarily written and graphical communication skills. The initial design course utilized the projects to experientially develop important skillsets, such as the design process, project management, verbal communication, teamwork, social considerations, and the application of scientific and mathematic principles. These skills were expected to be developed by the students, with limited guidance from the lab instructors and teaching assistants. While the open-ended nature of the projects in this course provided the students with the opportunity to display their unique skills, student feedback revealed that the course structure did not provide enough support and direction 
as was needed for learning the design process. Without the fundamental theoretical knowledge of a design process, the students tended to come up with solutions that were not practical for a real-world design challenge. Additionally, the students hadn't taken a sufficient number of technical engineering courses, with instruction in the application of mathematical and scientific principles to engineering design problems, in order to undertake many of the challenges presented in the projects.

\section{Revised Design Course}

In September 2010, the course structure was revised to consist of a single, consolidated design course, offered only in the first semester of the academic year. Given the decrease in the number of hours of design instruction given to the students, it was important that we accelerate the students' learning curve. Working under the premise that providing a theoretical framework of design prior to the lab projects would improve the students' design skills ${ }^{2}$, the revised course consists of 170 minutes of lab/workshop time and 150 minutes of lectures. In this revised structure, the lectures provide students with a theoretical foundation in design, project management, and communication. The workshops then contained short projects of increasing difficulty, allowing the students to apply their knowledge of the design process to new and unique challenges. Additionally, the projects were redesigned to utilize the students' logical and analytical abilities, rather than their technical knowledge from other courses. While this structure does not meet all of the learning outcomes from the previous structure, it provides the students with a more detailed foundation upon which to develop their design, project management, and communication skills.

\section{Criteria Development}

In order to obtain student feedback of the design courses, we utilized the most common form of descriptive study: surveys ${ }^{3}$. In 2009 and 2010 (the last year of the initial course structure and the first year of the revised course structure, respectively) the students were given an exit survey to gather data on what the students feel they learned from the course. Due to the increased likelihood of survey participants being identifiable, demographic information such as gender and GPA were not collected. The survey was divided into two sections, closed-ended questions and open-ended questions.

In the first section, the students were asked to rate their level of learning for various learning outcomes on a six-point Likert scale. The learning outcomes were primarily taken from the CEAB Graduate Attributes criteria ${ }^{4}$, most notably Problem Analysis (3.1.2), Design (3.1.4) and Communication Skills (3.1.7). These learning outcomes were then further refined, drawing from the detailed breakdowns in the CDIO Syllabus ${ }^{5}$, with a focus on Problem Identification and Formulation (2.1.1), System Thinking (2.3) and Communication (3.2).

In the second section of the survey, the students were asked to provide open-ended feedback on their likes and dislikes of the course. In the 2010 iteration of the survey, the students were also asked to provide open-ended feedback on what they felt they learned from the course, and what they felt the purpose of the course was. Drawing from Glaser and Strass' grounded theory ${ }^{6}$, in which qualitative data is categorized and relations between the categories form the basis of a 
theory, patterns/similarities in the students' responses have been identified to form categories of what the students value in their design education.

Analysis

Figures 2-16 illustrate the students' responses for each of the 15 questions asked in the first section of the survey. The survey was distributed to the approximately 700 students in each year of the design course, and in both years, approximately $20 \%$ of the students responded. The low response rate illustrates a flaw in voluntary surveys as a means to achieve a balanced response. However, the low response rate was deemed preferable to mandatory responses, in which the students may have felt pressured to answer more favourably, and cause greater bias to the results.

\begin{tabular}{|l|lll|}
\hline \multirow{3}{*}{ Legend } & $1=$ Strongly Agree & $2=$ Agree & $3=$ Slightly Agree \\
& $4=$ Slightly Disagree & $5=$ Disagree & $6=$ Strongly Disagree \\
& $7=$ NA/Declined to Answer & & \\
\hline
\end{tabular}

Figure 1. Legend of Likert scale responses

In Figures 2-5, the responses corroborated with our predictions that the increased focus on a theoretical foundation in design would increase the students' perceptions of their abilities to understand and apply the design to engineering challenges. Particularly, the theoretical foundation appears to have made a dramatic improvement in the students' understanding of a design process, as shown in Figure 2.

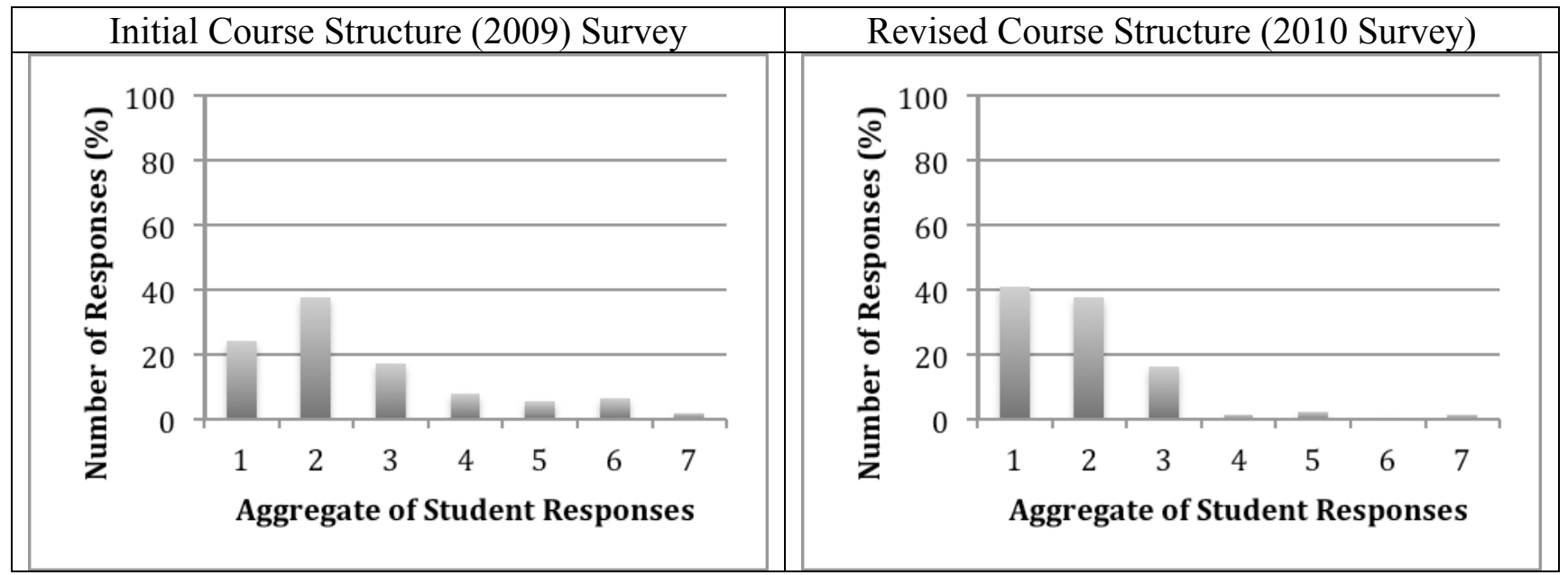

Figure 2. Student responses to the question "The [design course] introduced me to, or enabled me to further develop, the following skills: Understand a design process" 

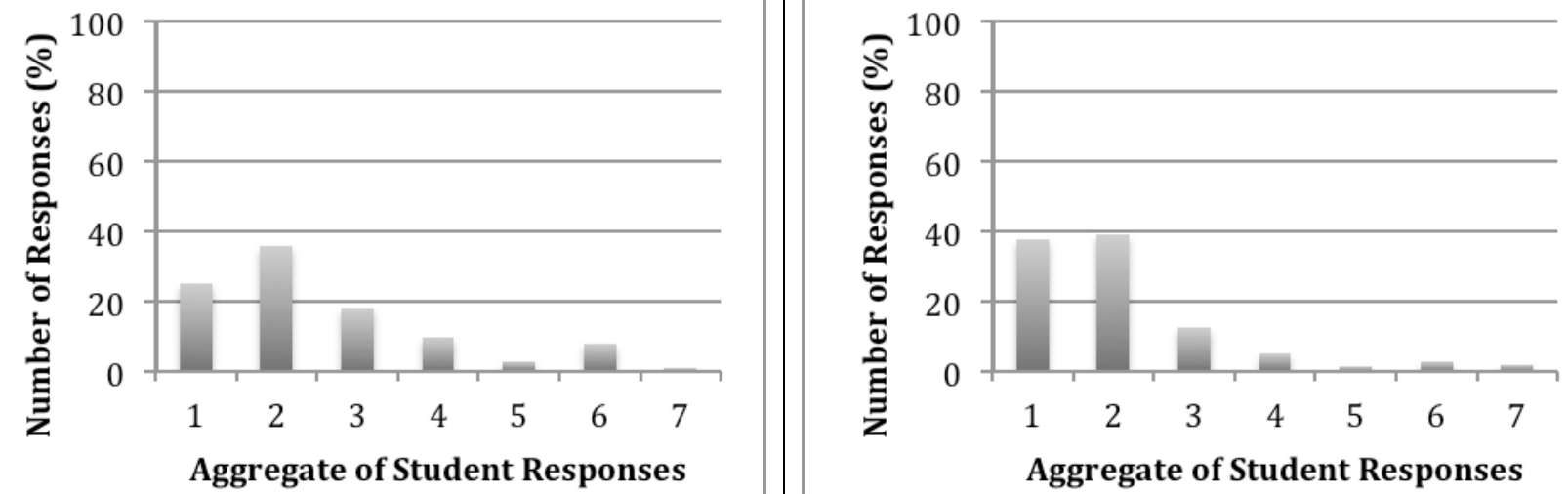

Figure 3. Student responses to the question "The [design course] introduced me to, or enabled me to further develop, the following skills: Apply a design process to a challenge"

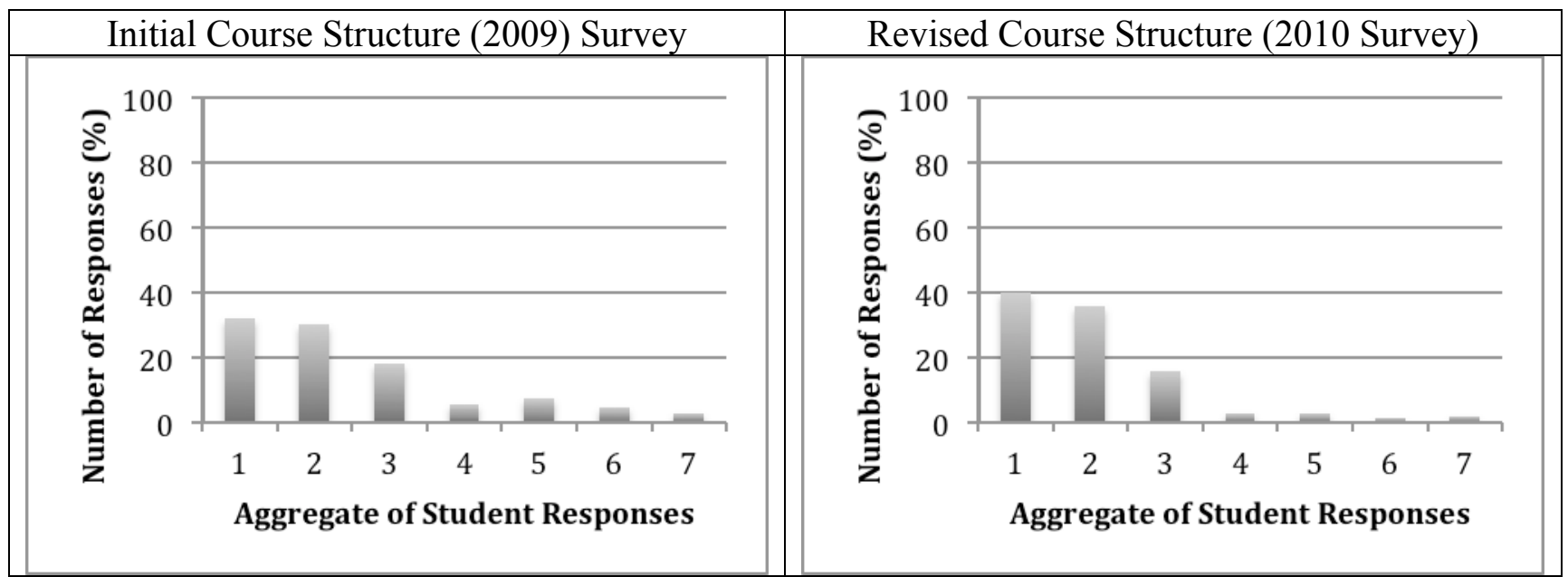

Figure 4. Student responses to the question "The [design course] introduced me to, or enabled me to further develop, the following skills: Evaluate a problem and brainstorm solutions"

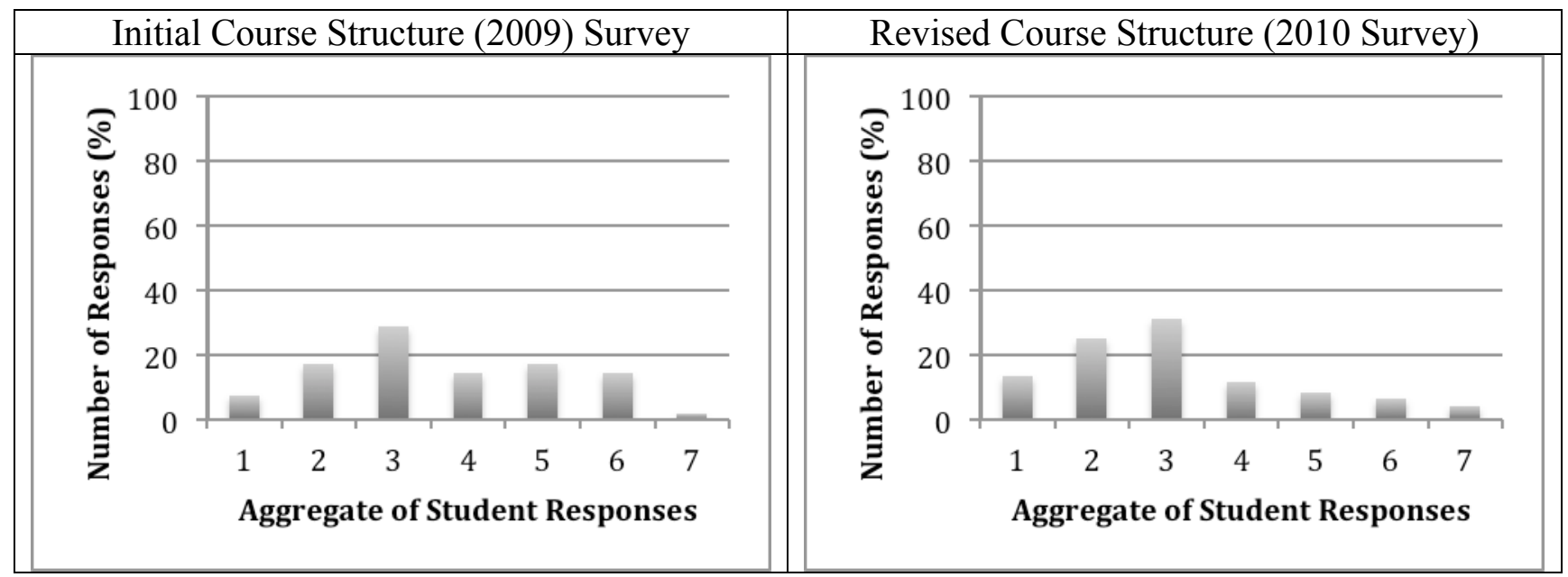

Figure 5. Student responses to the question "The [design course] introduced me to, or enabled me to further develop, the following skills: Analyze data in order to draw meaningful conclusions"

In Figures 6 and 7, we analyzed how the communications skills of the students differed between 
the two course implementations. While the increase in verbal communication was expected, due to its increased emphasis within the labs, the modest increase in the students' reporting of their written communication was surprising, since the students in the revised course structure did not get as many opportunities to practice written communication as the students in the initial course structure. This could potentially represent a bias of the results, if the students completing the survey for the revised course structure were more optimistic, or a discrepancy in the feedback the students were receiving on their written reports between the two course implementations.

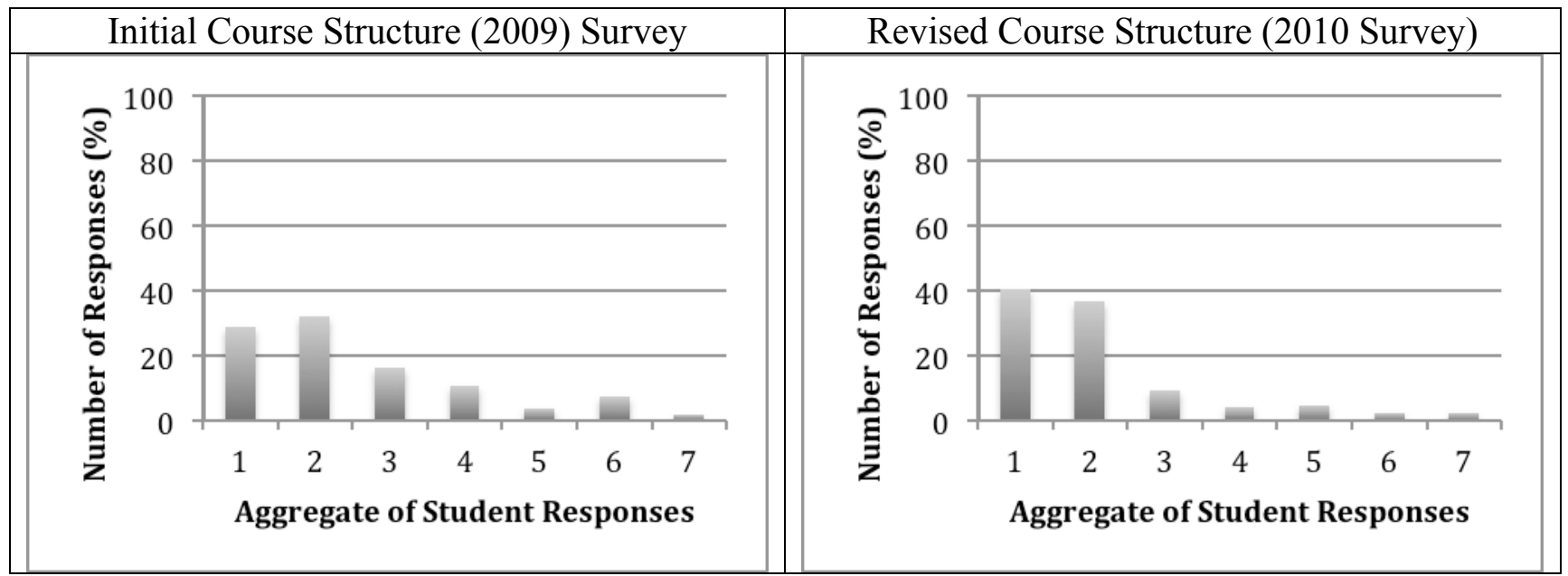

Figure 6. Student responses to the question "The [design course] introduced me to, or enabled me to further develop, the following skills: Communicate effectively in a verbal medium, such as team meetings or presentations"

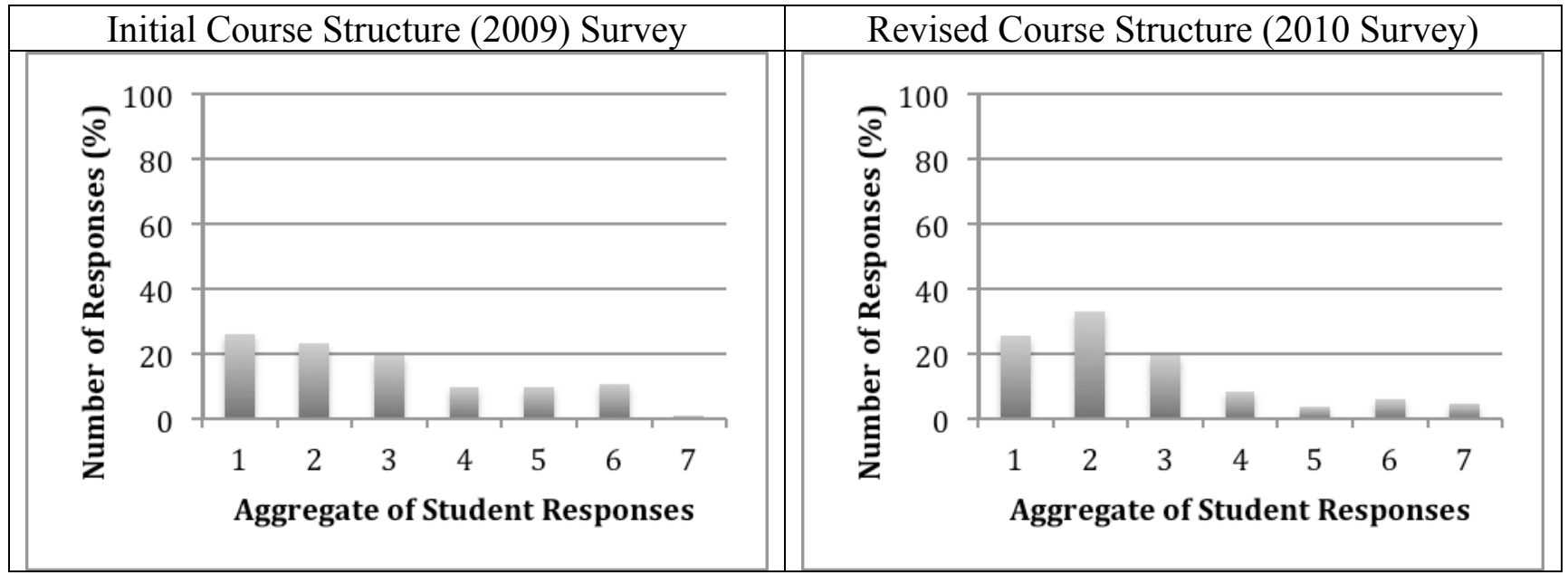

Figure 7. Student responses to the question "The [design course] introduced me to, or enabled me to further develop, the following skills: Communicate effectively in a written medium, such as reports"

With the revised course structure, students were asked to detail their navigation through the design process in their logbooks, which were then inspected by the teaching assistants at the conclusion of each project. Since this level of structure was not present in the initial design course, the increase of favourable responses from the revised structure in Figure 8 is reasonable. 


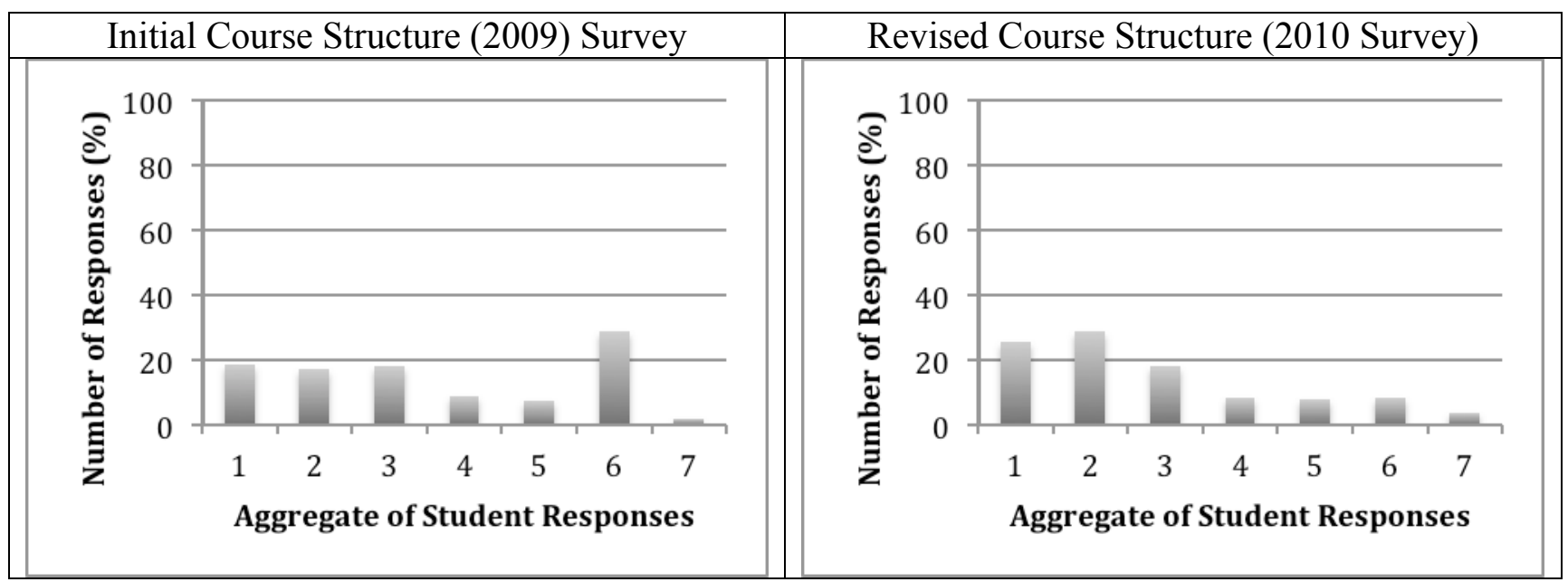

Figure 8. Student responses to the question "The [design course] introduced me to, or enabled me to further develop, the following skills: Understand the purpose of a logbook"

In Figures 9-11, despite the fact that the revised course structure placed a heavy emphasis in lectures on teamwork and project management, the increases in favourable responses were not as high as expected. This could counter our earlier supposition that the students participating in the revised course structure survey were more optimistic. It could also provide evidence that the integrated learning style of the initial course structure was successful for these particular skills.

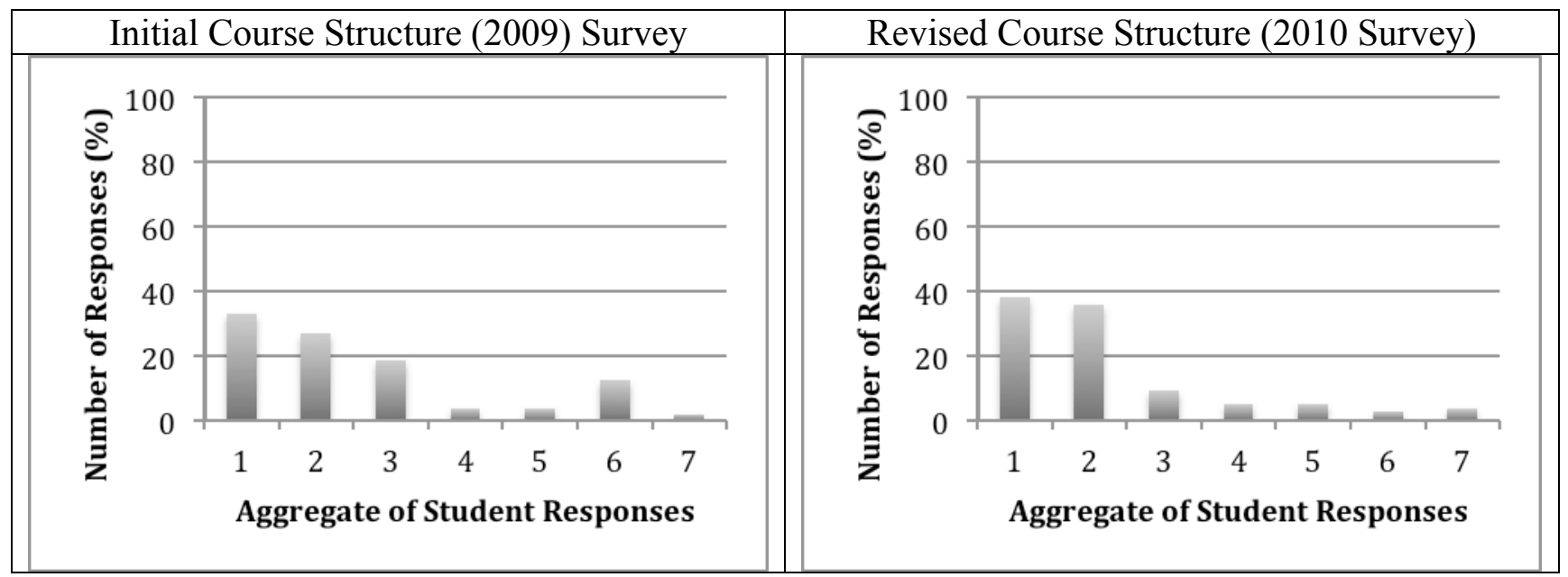

Figure 9. Student responses to the question "The [design course] introduced me to, or enabled me to further develop, the following skills: Understand techniques for time management" 


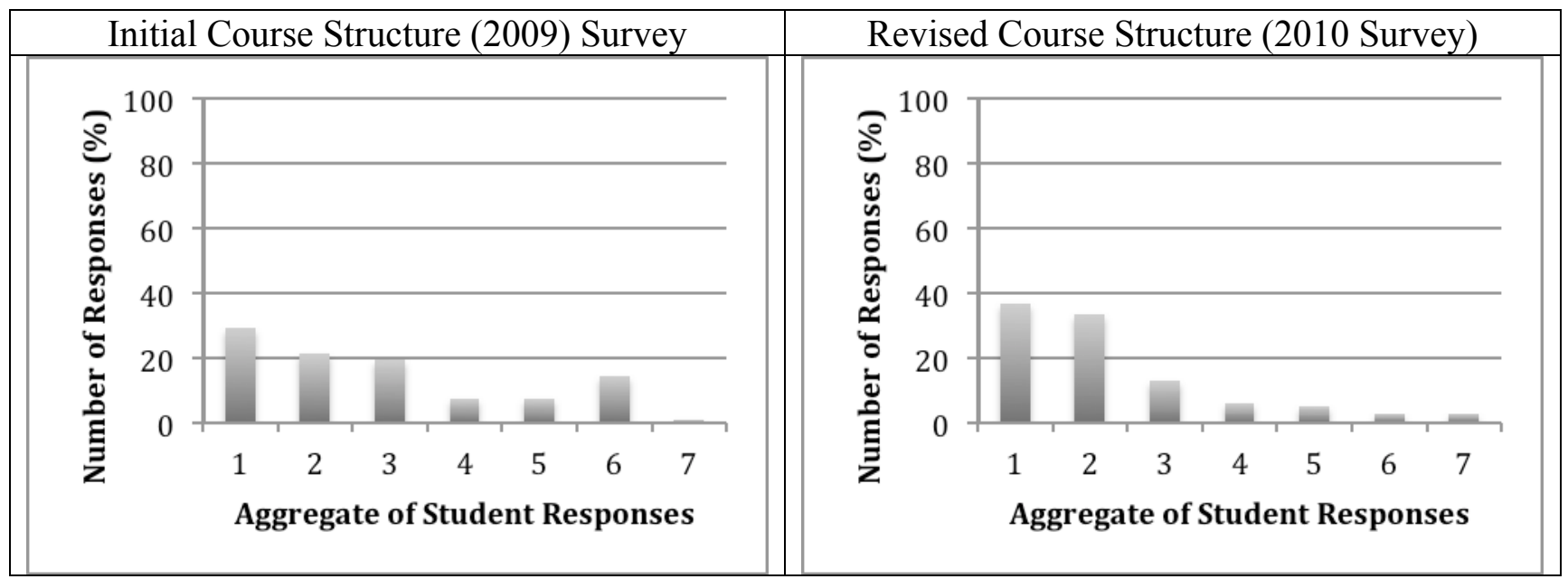

Figure 10. Student responses to the question "The [design course] introduced me to, or enabled me to further develop, the following skills: Apply techniques for time management”

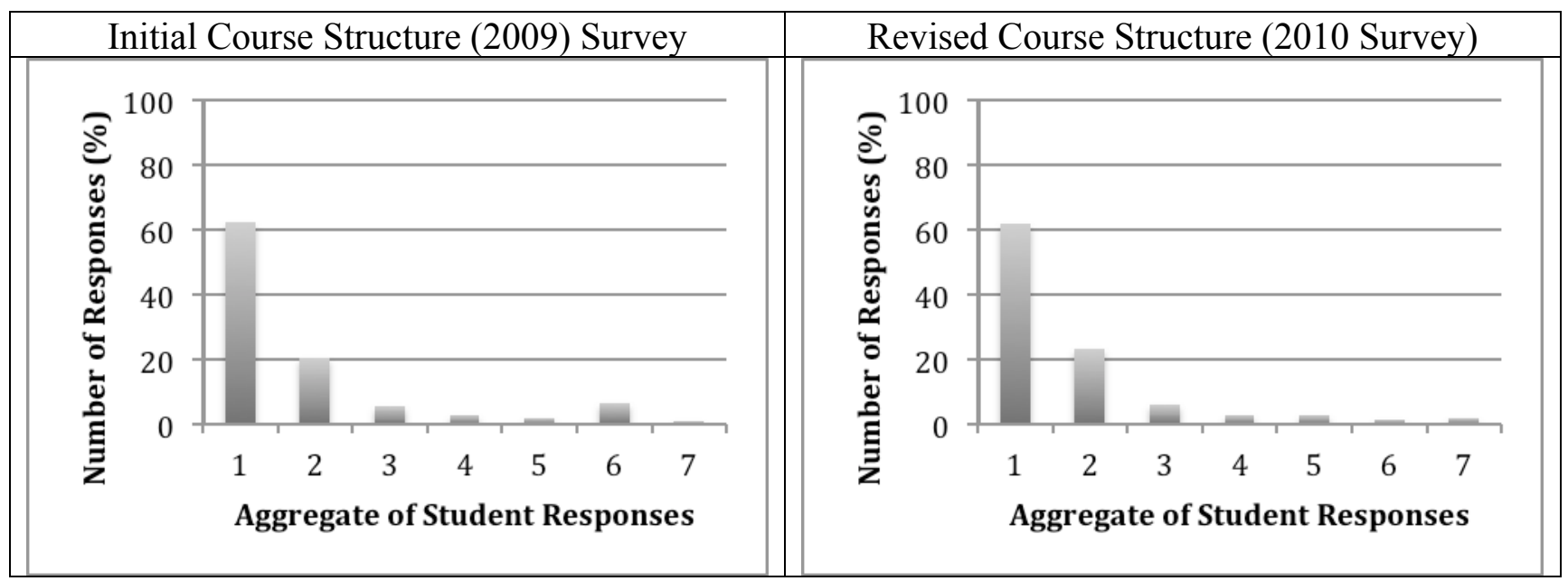

Figure 11. Student responses to the question "The [design course] introduced me to, or enabled me to further develop, the following skills: Work in a team environment"

Figures 12-16 show the most surprising results of this evaluation. While the projects for the initial design course were designed to integrate the skills evaluated in these figures, these skills were not addressed in the revised design course. Therefore, the improvement in favourability of these skills indicate that the participants of the 2010 survey were likely more optimistic than the participants of the 2009 survey. Additionally, these results provide evidence that the survey questions may not have been clearly understood by the survey participants. 

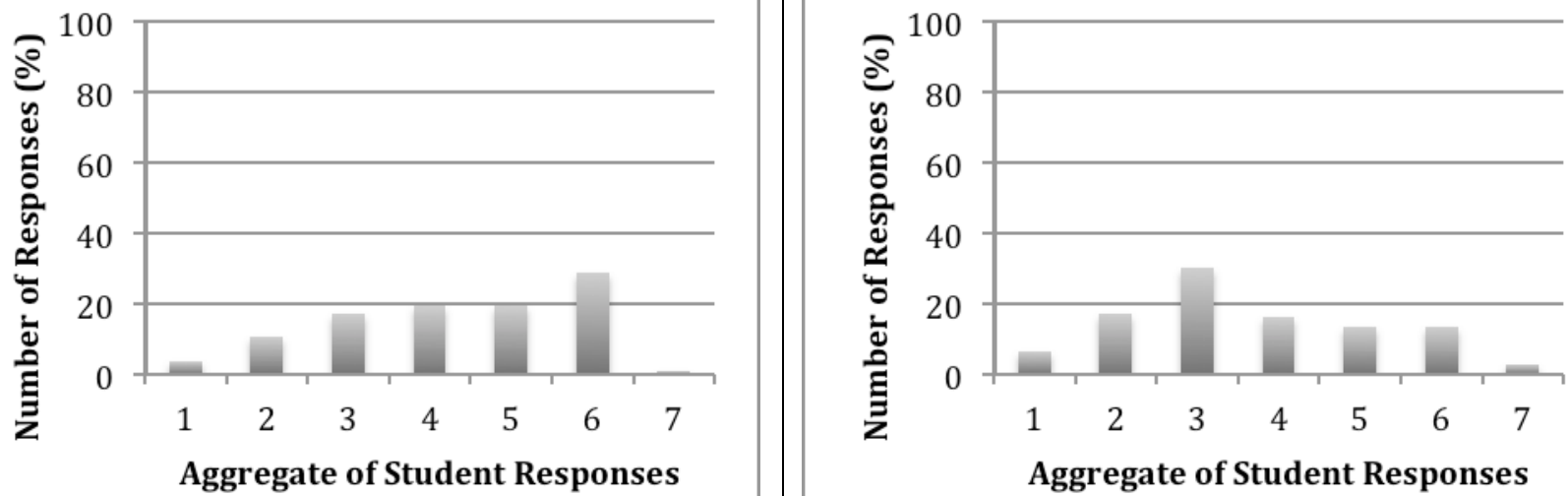

Figure 12. Student responses to the question "The [design course] introduced me to, or enabled me to further develop, the following skills: Apply principles of mathematics and natural sciences to real-world problems"

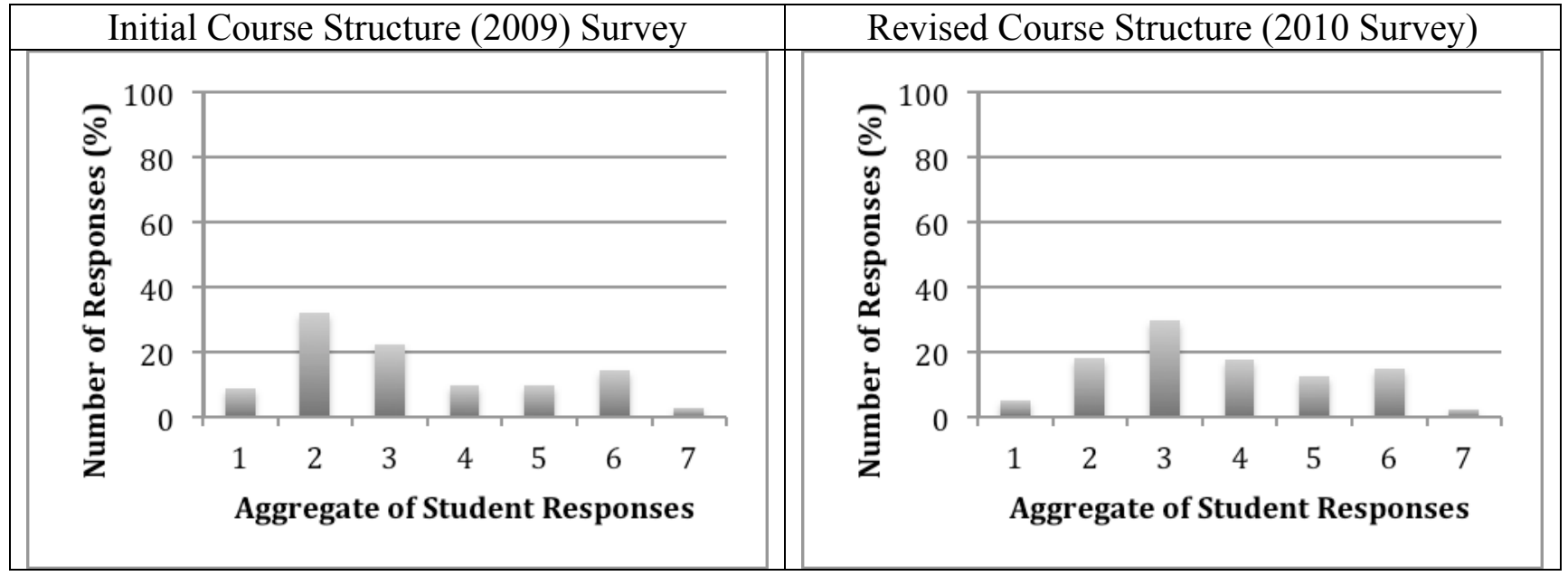

Figure 13. Student responses to the question "The [design course] introduced me to, or enabled me to further develop, the following skills: Take cultural issues into consideration for the design solution"

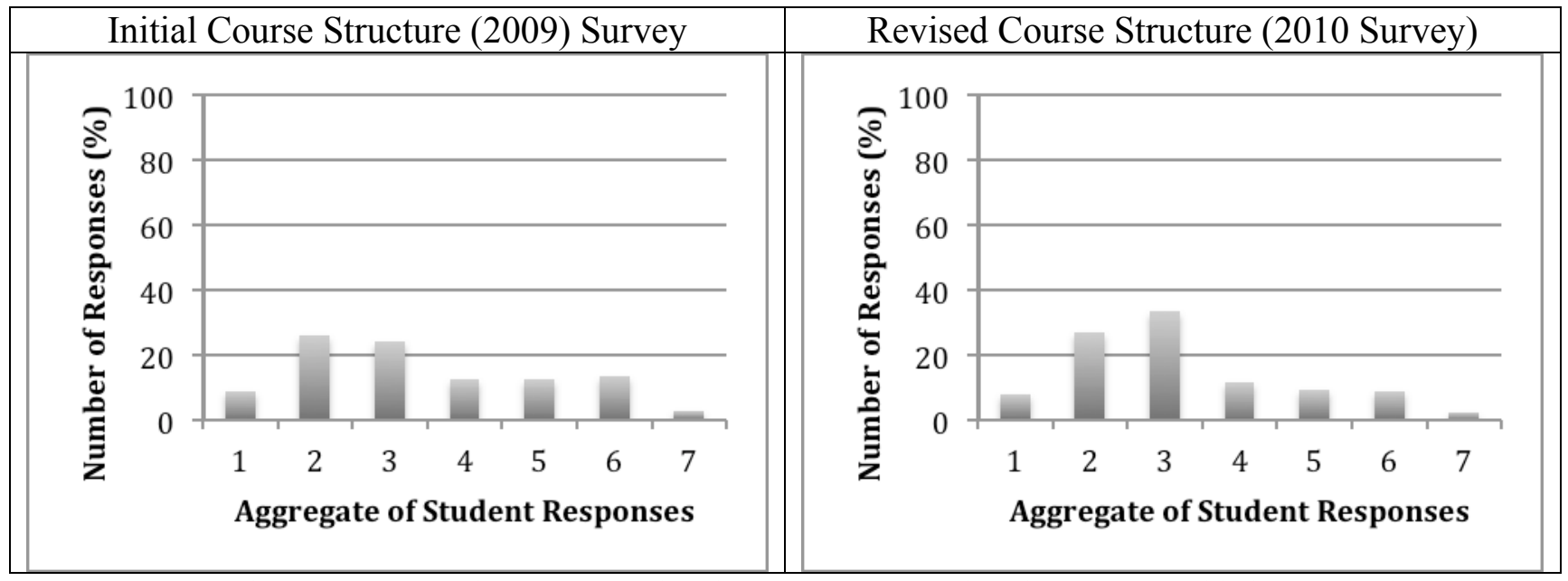

Figure 14. Student responses to the question "The [design course] introduced me to, or enabled me to further develop, the following skills: Take environmental issues into consideration for the design solution" 


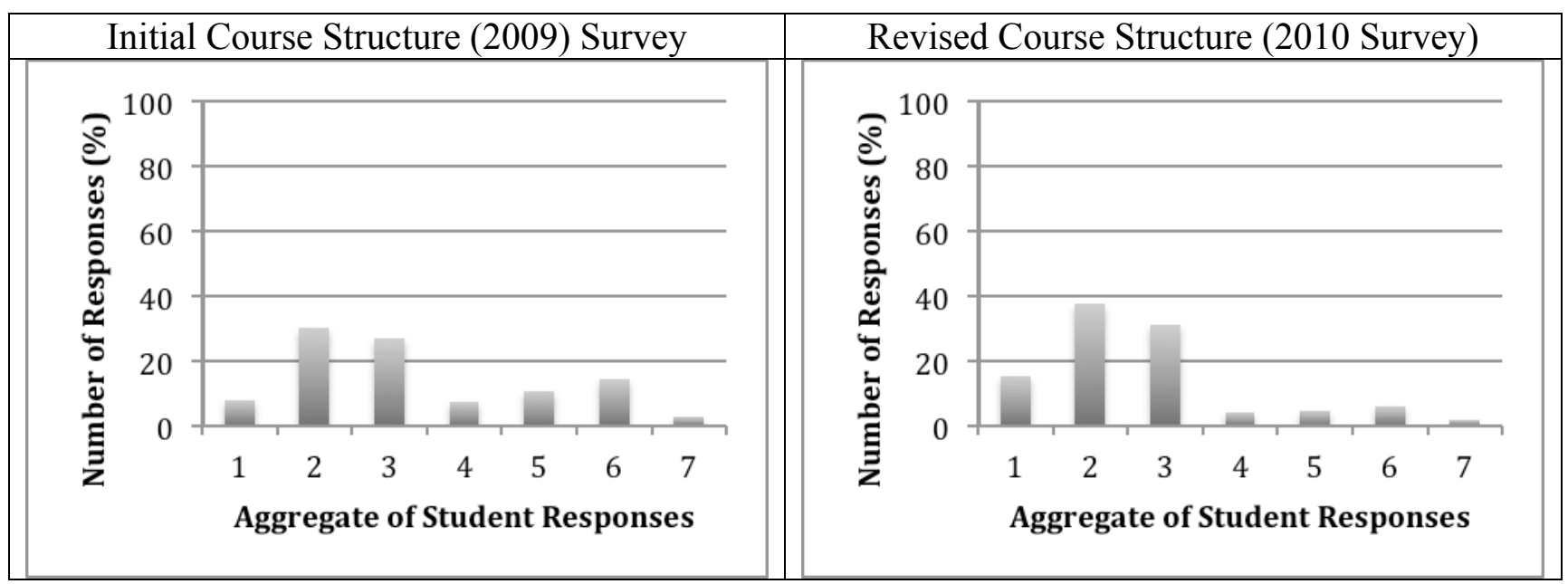

Figure 15. Student responses to the question "The [design course] introduced me to, or enabled me to further develop, the following skills: Take economic issues into consideration for the design solution"

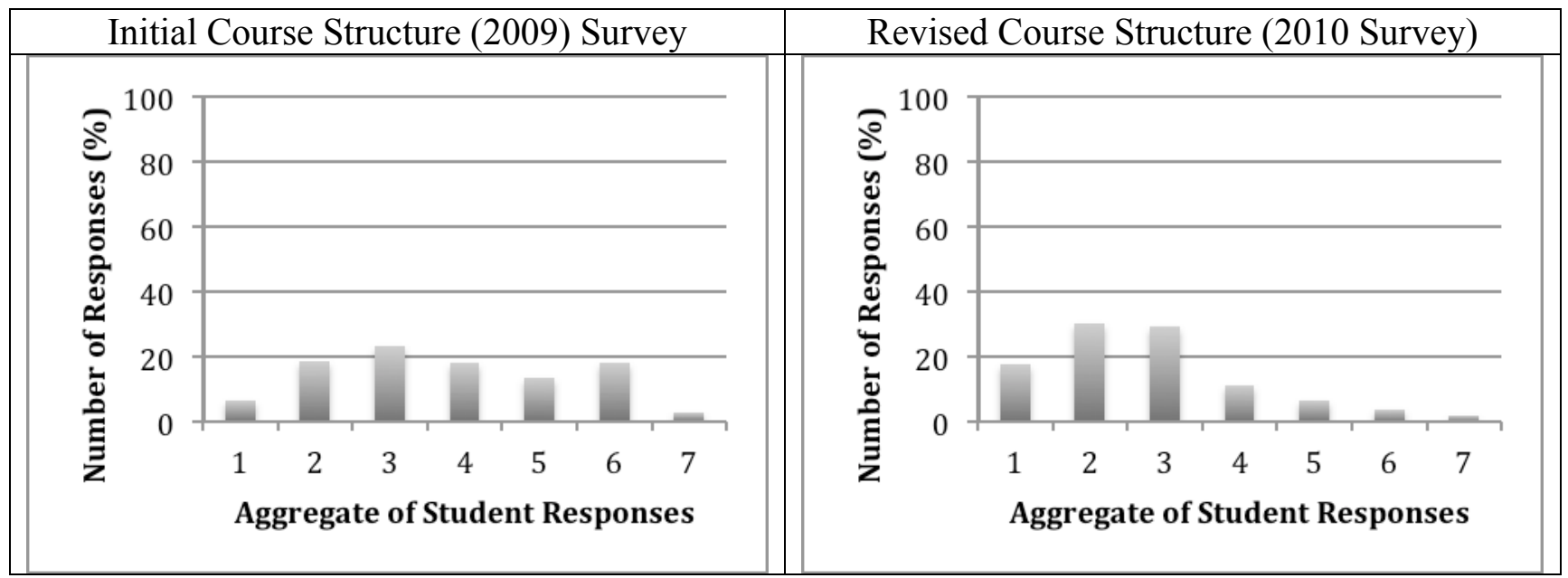

Figure 16. Student responses to the question "The [design course] introduced me to, or enabled me to further develop, the following skills: Take safety issues into consideration for the design solution"

From the closed-ended responses, some discrepancies between the predicted responses and the actual responses were noted. This could provide indication of the following occurrences:

- The attitudes of the survey participants between the two years were very different and could have biased the results.

- The closed-ended survey questions were not designed, or written in such a way that they were clear to the students.

- The theoretical foundation in engineering design possessed by the students in the revised design course enabled them to develop skills that are related to engineering, without the skills being explicitly taught.

In order to obtain a more accurate depiction of the reason for the discrepancies, the open-ended responses of the survey participants can be analyzed.

Following Glaser and Strauss' guide on grounded theory ${ }^{6}$, the 2009 open-ended responses were 
categorized into the following likes and dislikes about the initial course structure:

Likes:

- The opportunity to construct challenging and engaging projects.

- The opportunity to meet, and work with, new people.

- The opportunity for creative problem solving.

- The opportunity to learn and practice communication skills, both within the lectures, and in the projects.

- The opportunity to use standard engineering tools (such as logbooks).

- The application of design to real-world problems.

- The ability to easily receive a high grade.

Dislikes:

- Projects requiring too much social consideration, or too much reliance on pre-requisite technical skills.

- Vague project requirements and marking schemes.

- High workload.

- Stagnant communications assignments.

- Lack of support in projects.

In analyzing these results, we could make the argument that the participants' reported dislike for the "projects requiring too much social consideration, or too much reliance on pre-requisite technical skills" could have altered their perceptions of their learning of these skills, leading to lower reported scores for these skills in the closed-ended portion of the survey. Additionally, the "stagnant communications assignments" could indicate that a lack of continual challenge lowered the students' perceptions of their written communication skills. However, while the analysis of the open-ended responses can help to explain the discrepancies in the closed-ended responses, the analysis also illuminates the fact that the closed-ended surveys by themselves cannot provide an accurate depiction of what the students learned in the initial structure of the design course.

Similarly, the 2010 open-ended responses were analyzed and categorized into the following likes and dislikes about the revised course structure, as well as students' perceptions of the desired learning outcomes of the course:

Likes:

- The opportunity to construct challenging and engaging projects.

- The opportunity to meet, and work with, new people.

- The opportunity for creative problem solving.

- The opportunity to learn and practice communication skills.

- The opportunity to use standard engineering tools (such as logbooks).

- The lack of technical pre-requisite knowledge needed to complete the projects.

- The application of design to real-world problems.

- The opportunity to apply the design process to a challenge.

- The introduction to professional elements of engineering. 
- The opportunity to apply project management techniques to a design challenge.

Dislikes:

- The overwhelming amount of material presented in lectures.

- The simplicity of the projects, in comparison to the complex theoretical information being taught.

- Inflexible marking schemes.

- High workload.

Perception of the Course's Desired Learning Outcomes:

- The design process.

- Working in a team environment.

- Project/time management.

- Effective communication (verbal, written, and graphical).

- Creative thinking/brainstorming.

- The application of mathematical, and scientific principles to a design challenge.

- Critical evaluation of ideas.

- The importance of professionalism in engineering.

From these results, we can see that the students recognized many of the student learning outcomes for which we predicted improvements, as a focus of the course. Furthermore, the students identified additional learning outcomes that had not been established by the instructors as a focus of the course. We could therefore make the claim that, as the students recognized the importance of professionalism in engineering, they were able to translate that professionalism into consideration for cultural, environmental, economic, and safety issues when addressing a design challenge. However, these results equivalently show that the attitudes of the participants of the 2010 survey were more positive than those of the 2009 survey.

\section{Conclusions and Future Work}

Regardless of potential biases to the data, both the closed-ended and the open-ended responses indicate that greater development of the intended learning outcomes were achieved in the revised course structure. This supports our initial claim that by explicitly teaching students the theoretical foundations of engineering, they will report a greater development of the student learning outcomes than those students who have been expected to develop the skills through indirect contact in design projects. Additionally, the feedback from these studies has enabled us to begin further refinement on the new implementation of the design course, which will be elaborated upon in future work.

The unpredicted discrepancies between the results of the two surveys indicate that using different students introduces too much variability to make a direct comparison between the two course structures. However, since it is not possible to have the same students participate in both implementations of the course, we must employ other measures to obtain a more accurate representation of the true learning outcomes of the course structures. Therefore, in future research, additional refinement of the CEAB graduate attributes and the CDIO Syllabus should be undertaken, such that the intended meaning of the survey questions can be conveyed 
concisely to the students. Additionally, the results from the surveys will be triangulated with other data sources, such as interviews with the course instructors/teaching assistants, and focus groups that were done with the students during the term. This will allow us to compare and validate the students' self-reported learning outcomes, with the learning outcomes as perceived by the instructors, as well as to compare the students' self-reported learning outcomes at the conclusion of the semester, with their self-reported learning outcomes in the middle of the semester. Ideally, we would also like to perform follow-up surveys for the 2009 and 2010 survey participants in their capstone year (2012-2014), in order to compare and track their perceptions of their design education throughout their years at the Schulich School of Engineering, University of Calgary.

Finally, the remaining factor that has yet to be addressed in this paper is the dependency on the students' and instructors' perception of the development of student learning outcomes. This leads to the possibility of students not reporting skills they have developed through indirect learning, or reporting skills that they have been explicitly introduced to, but have not had a chance to properly develop. To overcome this obstacle, the students' final exam results in the course can provide an additional, objective, indicator of the learning outcomes developed by the students in the revised first year design course.

Bibliography

1. Sparkes J., Engineering education in a world of rapidly changing technology", AEESEAP/ FEISEAP/IACEE Int. Conf. Engineering Education, Singapore, 1993.

2. C. J. Atman, K. M. Bursic, “Teaching Engineering Design: Can Reading a Textbook Make a Difference?”, Research in Engineering Design, 1996, pp.240-250.

3. B. Olds, B. Moskal, and R. Miller, "Assessment in Engineering Education: Evolution, Approaches, and Future Collaborations", Journal of Engineering Education, 94,1, Jan 2005, pp. 13-25.

4. “Accreditation Criteria and Procedures 2008”, Canadian Engineering Accreditation Board, 2008, http://www.engineerscanada.ca/e/files/report_ceab_08.pdf

5. "CDIO Syllabus", CDIO, http://www.cdio.org/framework-benefits/cdio-syllabus

6. Glaser, B., \& Strauss, A. L. (1967). The discovery of grounded theory: Strategies for qualitative research. New York: Aldine de Gruyter. 